\title{
PENERAPAN METODE RAD DALAM PERANCANGAN (SIREMEDI) PADA KLINIK HALO FISIO
}

\author{
Duwi Cahya Putri Buani ${ }^{1}$, Indah Suryani $^{2}$ \\ ${ }^{12}$ Teknik Informatika, Sekolah Tinggi Manajemen Informatika dan Komputer \\ Indonesia \\ Email :duwi.dcp@nusamandiri.ac.id
}

\begin{abstract}
Halo Fisio Clinic is a clinic that provides health services in the field of physio therapy provided to general patients and athletes. Halo Fisio Clinic has been established since 2016 but the Halo Fisio Clinic does not have an information system so that administrative activities are still using manuals, this has resulted in many obstacles that occur in the clinic. The obstacles that often occur are loss of documents, slow service and difficult in conducting data search. Halo Fisio Clinic requires an information system that can solve these problems, therefore a Medical Record Information System (SIREMEDI) was designed, this system was designed using the RAD (Rapid Application Development) method, the RAD method is a software development method whose steps are easy to follow along with using the RAD method the system documentation can be done well.
\end{abstract}

Keywords: Medical Records, Information Systems, RAD

\begin{abstract}
Abstrak
Klinik Halo Fisio merupakan klinik yang menyediakan pelayanan kesehatan dalam bidang fisio terapi yang diberikan kepada pasien umum serta olahragawan. Klinik halo fisio sudah berdiri sejak 2016 tetapi klinik halo fisio belum memiliki sistem informasi sehinga kegiatan administrasi masih menggunakan manual, hal ini mengakibatkan banyak kendala yang terjadi diklinik tersebut kendala yang sering terjadi adalah kehilangan dokumen, pelayanan lambat dan sulit dalam melakukan pencarian data. Klinik halo fisio membutuhkan sebuah sistem informasi yang dapat menyelesaikan permasalahan-permasalahan tersebut oleh karena itu dirancanglah Sistem Informasi Rekam Medis (SIREMEDI), sistem ini dirancang dengan menggunakan metode RAD (Rapid Aplication Development), metode RAD merupakan metode pengembangan perangkat lunak yang langkah-langkahnya mudah untuk diikuti serta dengan menggunakan metode RAD pendokumentasian sistem dapat dilakukan dengan baik.
\end{abstract}

Kata Kunci: RAD, Rekam Medis, Sistem Informasi 


\section{Introduction}

Klinik Halo Fisio merupakan klinik yang bergerak dalam bidang jasa pengobatan fisioterapi. Klinik Halo Fisio menerapkan direct access atau pelayanan langsung tanpa adanya rujukan dari dokter, Hal ini berkaitan dengan respon waktu, efektifitas dan efisien pelayanan terhadap pasien yang terdiri dari masyarakat olahraga, atlet, maupun masyarakat umum. Pendiri klinik ini adalah Adinda Priscilla (Cia) yang sudah berpengalaman sebagai fisioterapi olahraga dan dibantu oleh rekan kerja yang berpengalaman sebagai fisioterapi di lingkungan olahraga dan rumah sakit, maka terbentuklah Halo Fisio pada 6 Januari 2016.

Sejak berdiri pada tahun 2016 klinik halo fisio memiliki lebih dari 100 pasien yang perlu penanganan secara cepat dan tepat. Klinik halo fisio masih menggunakan sistem konvensional yang mengakibatkan kurang efektif dan efesien dalam pelayanannya (Sahab \& D, 2015). Selain kurang efektif dan efesien sistem konvensional juga kurang dapat diandalkan dalam pengolahan data antara lain pencarian data, pencatatan data serta pimpinan sulit melakukan pengambilan keputusan (Yusri, 2015).

Klinik Halo Fisio membutuhkan sistem baru yang dapat menyelesaikan permasalahan salah satunya adalah dengan merancang sistem informasi rekam medis. Dengan adanya sistem informasi, organisasi atau perusahaan dapat menjamin kualitas informasi yang disajikan dan dapat mengambil keputusan berdasarkan informasi tersebut (Syafarina, 2016).

Dengan penggunaan Sistem Informasi Rekam Medis diharapkan Klinik Halo Fisio dapat berkembang lebih baik serta permasalahan yang sebelumya terjadi dapat diatasi.

\section{Materials and Methods}

Untuk memperoleh data yang akurat, maka penulisan ini menggunaka beberapa metode sebagai sarana untuk membantu serta memudahkan penulis dalam penyusuna. Berbagai macam metode yang penulis gunakan diantaranya adalah:

\subsection{Teknik Pengumpulan Data}

1) Observasi

Observasi merupakan teknik pengumpulan data dengan cara datang langsung ke klinik HALO FISIO yang berada di Jalan Taman Kebon Jeruk Blok A.I No 21, Jakarta Barat.

2) Wawancara

Wawancara merupakan teknik pengumpulan data dengan cara mengajukan pertanyaan-pertanyaan langsung kepada narasumbernarasumber terkait dengan informasi 
dan kebutuhan klinik, narasumber utama yaitu ibu Adinda Priscilla selaku ceo and founder klinik HALO FISIO.

3) Metode Penelitian Kepustakaan

Metode Kepustakaan adalah melakukan pengumpulan data teoritis dari jurnal, e-library, internet dan buku-buku yang mendukung penulisan dengan mencari referensi yang berkaitan dengan perancangan sistem informasi klinik tersebut.

2.2 Metode Pengembangan Perangkat Lunak

Model perangkat lunak yang digunakan dalam penelitian ini adalah model RAD (Rapid Aplication Development), ada 3 tahapan metode RAD (Rapid Aplication Development) (Noertjahyana, 2002).

1) Rencana Kebutuhan (Requirement Planning).

Pada tahap ini, user dan analyst melakukan semacam pertemuan untuk melakukan identifikasi tujuan dari aplikasi atau sistem dan melakukan identifikasi kebutuhan informasi untuk mencapai tujuan.

2) Proses Desain (Design Workshop) Pada tahap ini adalah melakukan proses desain dan melakukan perbaikan-perbaikan apabila masih terdapat ketidaksesuaian desain antara user dan analyst.

\section{3) Implementasi (Implementation)}

Setelah desain dari sistem yang akan dibuat sudah disetujui baik itu oleh user dan analyst, maka pada tahap ini programmer mengembangkan desain menjadi suatu program. Setelah program selesai baik itu sebagian maupun secara keseluruhan, maka dilakukan proses pengujian terhadap program tersebut apakah terdapat kesalahan atau tidak sebelum diaplikasikan pada suatu organisasi. Pada saat ini maka user bisa memberikan tanggapan akan sistem yang sudah dibuat serta persetujuan mengenai sistem tersebut.

\section{Results and Discussion}

3.1 Rencana Kebutuhan (Requirement Planning)

Dalam Sistem Informasi Rekam Medis Halo Fisio terdapat tiga user atau pengguna yang dapat berinteraksi dengan sistem, yaitu: Owner, Terapis dan Bagian Administrasi. Ketiga user atau pengguna memiliki karakteristik berbeda-beda serta memiliki kebutuhan informasi yang berbeda, seperti berikut:

1) Skenario Kebutuhan Owner

a) Mengelola Data Pasien

b) Mengelola Data Terapis

c) Mengelola Data Pengguna

d) Mengelola Data Paket

e) Mengelola Data Tindakan 
f) Mengelola Data Rekam Medis Pasien

g) Mengelola Laporan

2) Skenario Kebutuhan Terapis

a) Mengelola Data Rekam Medis Pasien

3) Skenario Kebutuhan Administrasi

a) Mengelola Pendaftaran Pasien

\subsection{Proses Desain (Design Workshop)}

Tahapan selanjutnya dalam perancangan Sistem Informasi Rekam Medis dengan Menggunakan metode RAD adalah Proses Desain, Proses desian dalam penelitian ini menggunakan UML (Unified Modeling Language) untuk melakukan perancangan sistem dan database. Sedangkan tools yang digunakan adalah EI (Enterprise Architecture).

1) Use Case Diagram

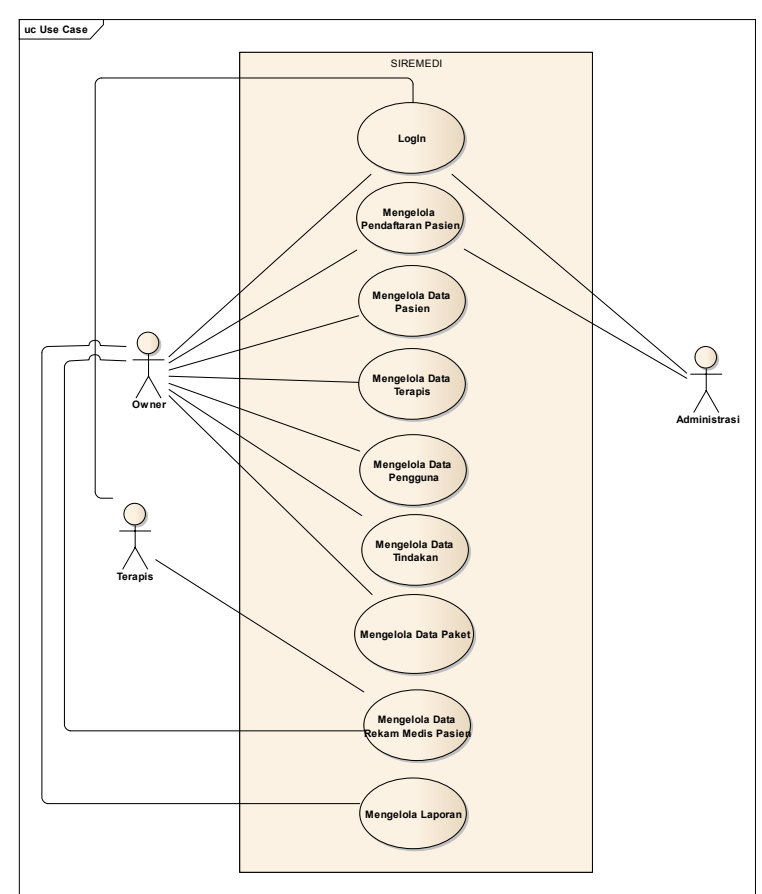

Sumber: (Buani \& Suryani, 2020)

Gambar 1 Use Case Diagram
2) Activity Diagram

a) Activity Diagram Mengelola Data Pasien

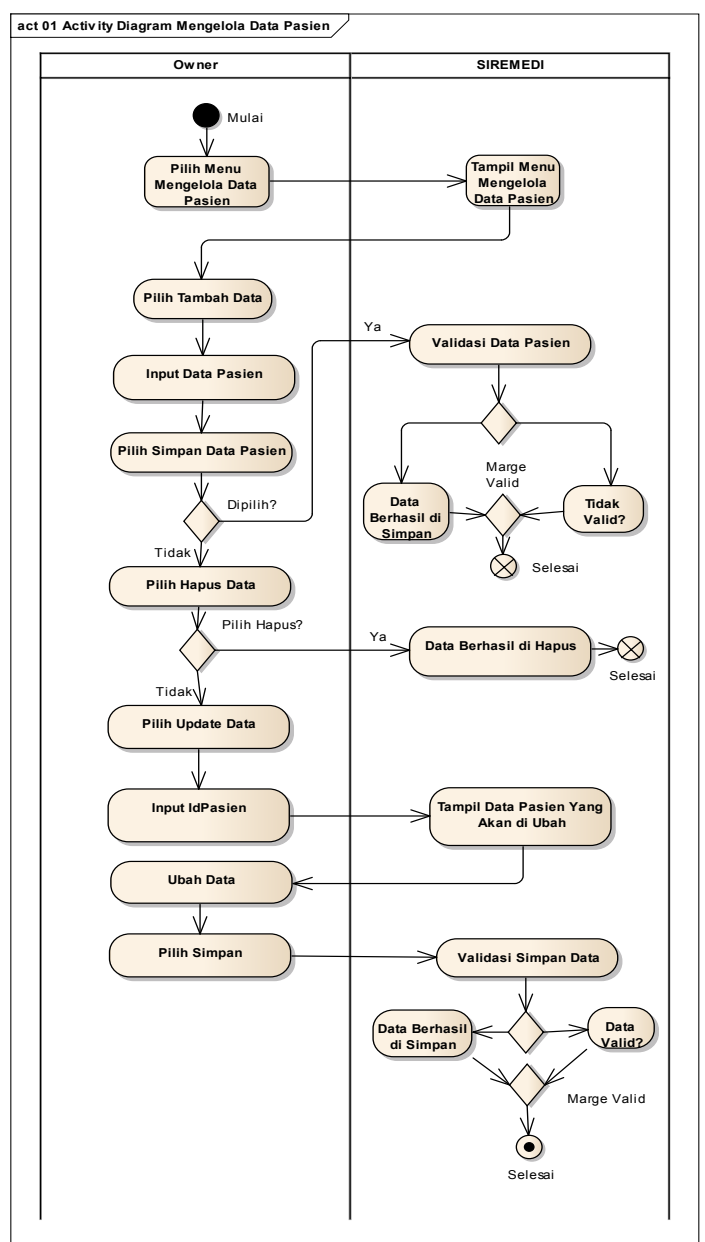

Sumber: (Buani \& Suryani, 2020)

Gambar 2 Activity Diagram Mengelola Data Pasien

b) Activity Diagram Mengelola Data Rekam Medis Pasien 


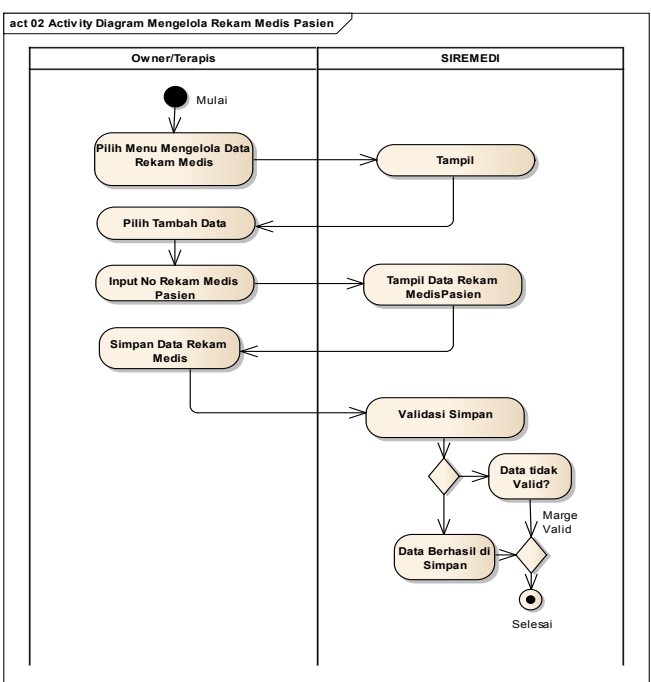

Sumber: (Buani \& Suryani, 2020)

Gambar 3 Activity Diagram Mengelola

\section{Rekam Medis}

3) Squance Diagram

a) Squance Diagram Mengelola Data Pasien

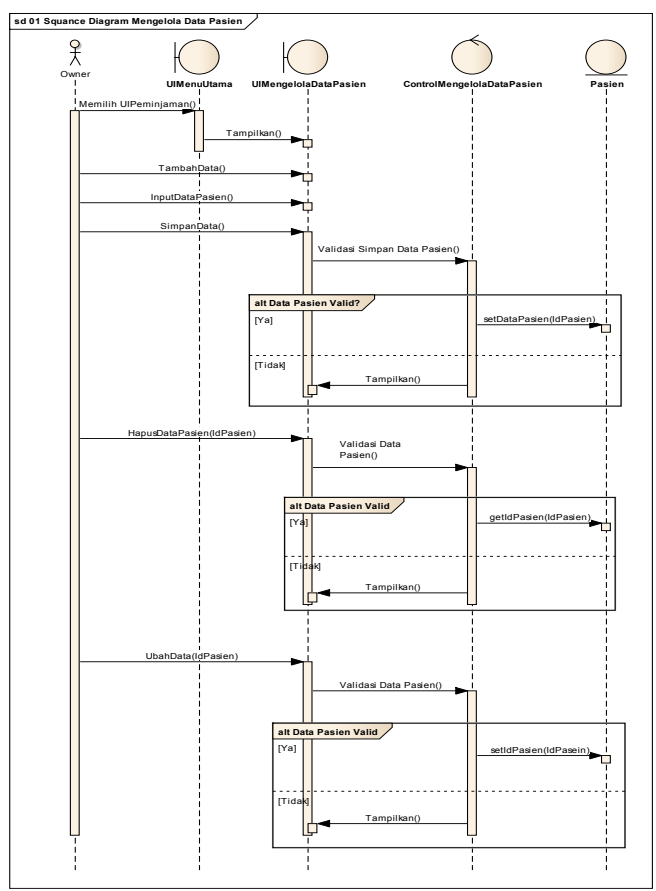

Sumber: (Buani \& Suryani, 2020)

Gambar 4 Squance Diagram Mengelola Pasien

b) Squance Diagram Mengelola Rekam Medis Pasien

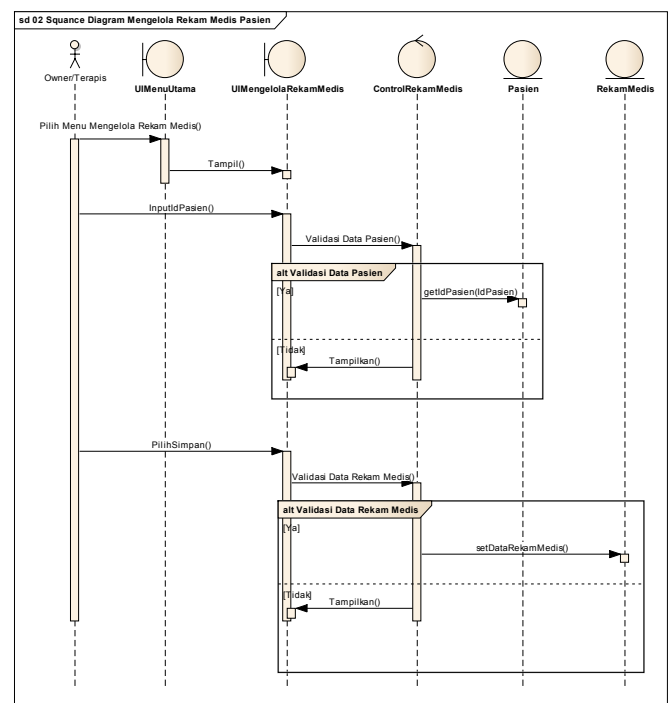

Sumber: (Buani \& Suryani, 2020)

Gambar 5 Squance Diagram Mengelola Data Rekam Medis

\section{4) Class Diagram}

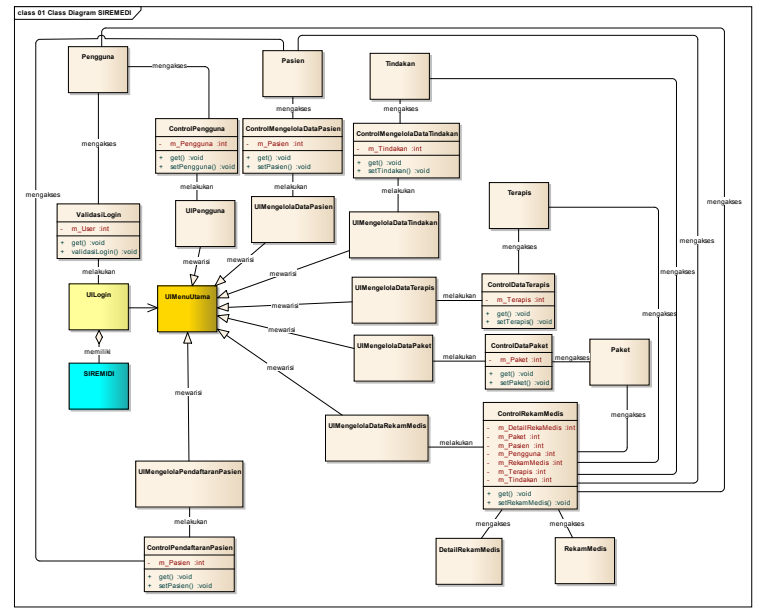

Sumber: (Buani \& Suryani, 2020)

Gambar 6 Squance Diagram Mengelola Data Rekam Medis

5) Deployment Diagram

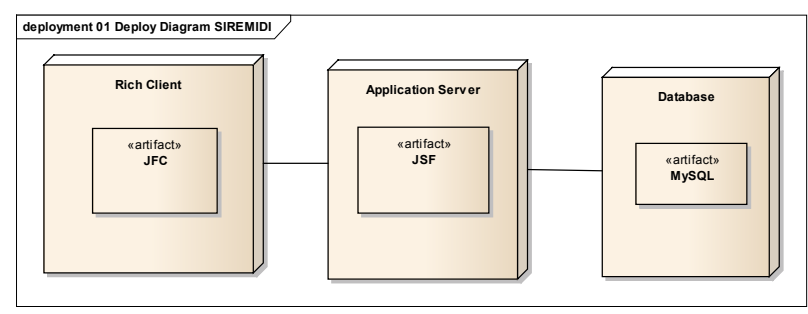

Sumber: (Buani \& Suryani, 2020) 
Gambar 7 Squance Diagram Mengelola

Data Rekam Medis

6) Data Model

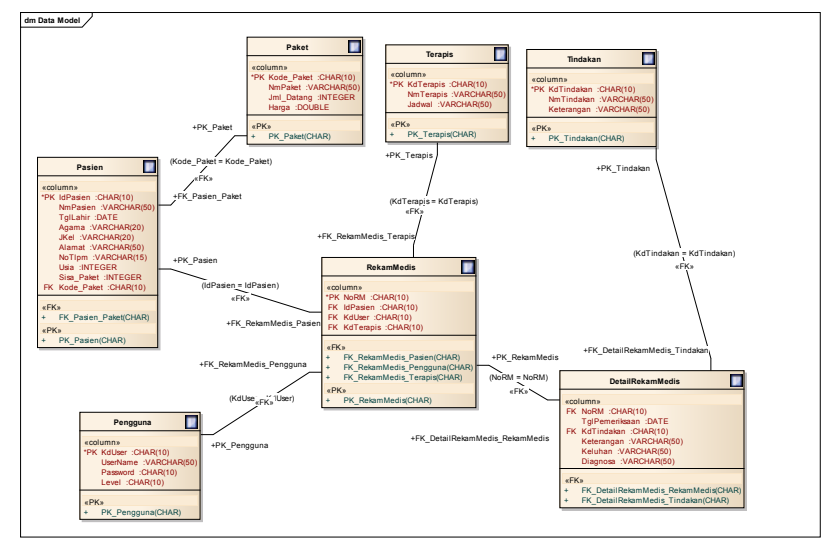

Gambar 8 Squance Diagram Mengelola

Data Rekam Medis

\subsection{Implementasi (Implementation)}

Tahapan terakhir dari metode RAD adalah Implementasi. Implementasi dalam penelitian ini menggunakan Bahasa pemrograman java dan tools yang digunakan adalah NetBeans IDE 8.2.

1) Form Mengelola Data Pasien

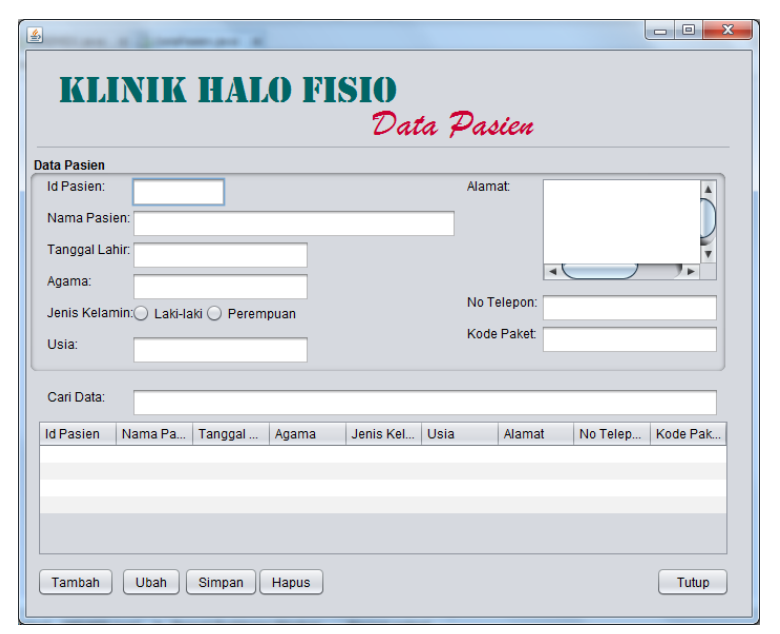

2) Form Data Rekam Medis Pasien

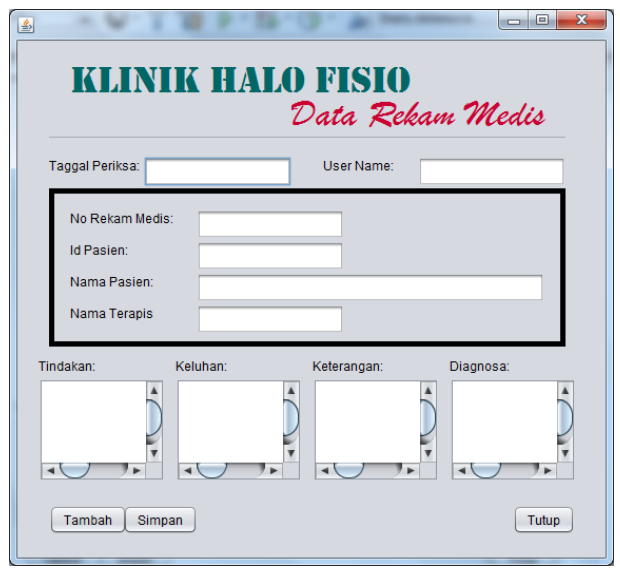

Gambar 9 Form Mengelola Data Pasien

\subsection{Kesimpulan}

Klinik Halo Fisio merupakan klinik yang sudah dipercaya banyak kalangan baik dari olahragawan samapi dengan masyarakat umum. Kepercayaan pasien terhadap klinik halo fisio menjadikan klinik tersebut berkembang menjadi klinik yang besar, sehingga klinik tersebut harus memperbaiki sistemnya. Penulis melakukan observasi secara langsung banyak kelemahan-kelemahan yang menghambat klinik halo fisio untuk berkembang. Untuk mengatasi permasalahan yang terjadi di klinik tersebut penulis merancang Sistem Informasi Rekam Medis (SIREMEDI). SIREMEDI dirancang menggunakan metode RAD (Rapid Aplication Development) yang setiap tahapannya mudah di ikuti. 


\subsection{Ucapan Terima Kasih}

Alhamdulillah puji syukur kami ucapkan kepada ALLOH SWT yang telah meridhoi kami dalam menyelesaikan Penelitian ini. Tak lupa juga kami ucapkan kepada pihak-pihak yang terlah membantu penelitian ini, kami harapkan penelitian ini bisa menjadi sebuah rujukan untuk penelitian selanjutnya.

\subsection{References}

Buani, D. C. P., \& Suryani, I. (2020). Laporan Akhir Penelitian Mandiri STMIK Nusa Mandiri Jakarta. Penelitian Dosen Yayasan.

Noertjahyana, A. (2002). STUDI ANALISIS RAPID APLICATION DEVELOPMENT
PERANGKAT LUNAK Agustinus Noertjahyana. Jurnal Informatika, 3(2), 74-79.

Sahab, A., \& D, W. M. P. (2015). PERANCANGAN

DAN

PENERAPAN SISTEM INFORMASI PERPUSTAKAAN SEKOLAH PADA SMAN 5 KEDIRI Pembahasan. Jurnal Ilmiah DASI, 16(1), 8-11.

Syafarina, G. A. (2016). PERANCANGAN APLIKASI INVENTORY BARANG MATERIALS DAN PRODUCT. Technologia, 7(1), 25-33.

Yusri. (2015). SISTEM INFORMASI PERPUSTAKAAN BERBASIS WEB PADA SMP FRATER MAKASSAR. JUPITER, XIV(2), 66-77. 